\title{
Electrochemical Determination of the Serotonin Reuptake Inhibitor, Dapoxetine, Using Cesium-Gold Nanoparticles
}

\author{
Mona A. Mohamed, ${ }^{\dagger}$ Shimaa A. Atty, ${ }^{\dagger}$ Ali M. Yehia, ${ }^{\dagger}$ Christopher W. Foster, ${ }^{\S}{ }^{\S}$ Craig E. Banks, ${ }^{*},{ }_{(}(0)$ \\ and Nageh K. Allam*,lli
}

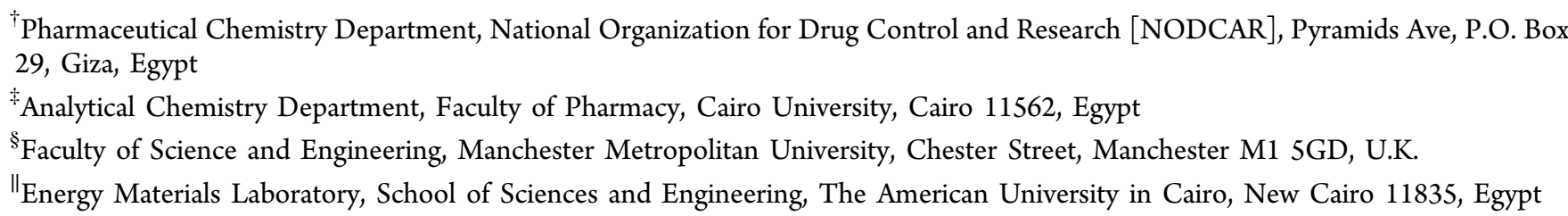

Supporting Information

ABSTRACT: Cesium-gold ( $\mathrm{Cs}-\mathrm{Au}$ ) nanoparticles are shown to be analytically advantageous for the electroanalytical sensing of dapoxetine (DPX), a serotonin reuptake inhibitor used for the treatment of premature ejaculation. The Cs-Au nanoparticles are electrically wired and supported upon mass producible, economical screen-printed electrochemical sensing platforms and are characterized electrochemically (cyclic voltammetry and electrochemical impedance spectroscopy) and physiochemically (field emission scanning electron microscopy and energy dispersive X-ray analysis). The face-centered design was applied to optimize the significant experimental factors by using square wave voltammetry. The Cs-Au-based sensor is found to exhibit a large linear range $\left(10^{-7}\right.$ to $\left.10^{-4} \mathrm{M}\right)$ with a good analytical linearity with the limits of detection and quantification corresponding to $2.50 \times 10^{-10}$ and $8.33 \times 10^{-8} \mathrm{M}$, respectively. The developed sensor was successfully applied in the quantification of DPX in the presence of sildenafil, both of which are commonly found within combined dose tablet pharmaceutical formulations. The proposed DPX electrochemical Cs-Au-based sensor has the advantages of being single-shot and disposable and is shown to be successful in determining DPX in pharmaceutical formulations, human urine, and serum samples with acceptable recoveries.

\section{INTRODUCTION}

The World Health Organization has defined premature ejaculation (PE) as "persistent or recurrent ejaculation with minimal stimulation before or shortly after penetration and before the person wishes it, over which the sufferer has little or no voluntary control, which causes the sufferer and/or his partner bother or distress." ${ }^{1,2}$ PE prevails in over $20-30 \%$ of men, ${ }^{3}$ and its probability is high in young adults and adolescents. ${ }^{4}$ Dapoxetine (DPX), [(S)-N,N-dimethyl-3-(naphthalene-1yloxy)-1-phenylpropan-1-amine] is a selective serotonin reuptake inhibitor (SSRI) ${ }^{5}$ and was the first drug approved in 2008 for PE treatment in seven European countries. ${ }^{5,6}$ Henceforth, DPX has established marketing approval in 59 countries worldwide. Its safety and efficacy has also been substantiated by an extensive clinical development program of PE treatment., Erectile dysfunction (ED) is another male-associated sexual problem that is common in the elderly. ${ }^{8}$ The normal erectile function may be impaired due to several physical or psychological factors. Typical medications for $\mathrm{ED}^{9}$ promote penile blood flow, and enhance erectile function. ${ }^{6}$ Combinations of SSRI and PDE-5 inhibitors are common in many sexual health medications, in particular for PE. ${ }^{10,11}$
Regrettably, some of these medications may contain incorrect doses, and moreover, many health supplements contain undeclared agents. Food Drug Administration listed 355 undeclared sexual enhancement products, with $\sim 8 \%$ of them containing undeclared DPX and other PDE-5 inhibitors. ${ }^{12}$ This underlying problem has a detrimental effect on the general health care. Mild dizziness to serious death has been encountered as adverse effects of these counterfeit medications. ${ }^{13}$ The widespread availability of male sexual enhancers is a matter of concern. ${ }^{14,15}$ Hence, Lebel et al. ${ }^{16}$ developed a fast screening liquid chromatography-mass spectrometry (MS) methodology for the simultaneous identification of $71 \mathrm{ED}$ active ingredients and 11 natural ingredients present in counterfeited trademark products. ${ }^{16}$ Another study reported the high-performance liquid chromatography isolation of DPX from a health supplement powder sold in Singapore, along with structural elucidation using nuclear magnetic resonance,

Received: August 16, 2017

Accepted: September 11, 2017

Published: October 11, 2017 
infrared, high-resolution MS, and electrospray ionization mass spectrometry. ${ }^{17}$

Chromatographic methods have been reported for the analysis of DPX using either ultraviolet ${ }^{18-29}$ or fluorescence detection $^{30}$ as well as capillary electrophoresis. ${ }^{31}$ Ultraperformance liquid chromatography-MS/MS has also been reported for the quantification of DPX in biological fluids. ${ }^{5,32}$ Obviously, all these reported instrumental techniques are costly and demand professional training; analytically useful alternatives are sought after.

Electrochemical methods of analysis have shown to be accurate, sensitive, and cost-effective ${ }^{33}$ and can be applied for the determination of different analytes such as new psychoactive substances, ${ }^{34}$ proteins, ${ }^{35}$ and opioid drugs. ${ }^{36,37}$ Simple, rapid, inexpensive, and accurate testing devices should be made available to meet patients' convenience along with industrial needs. In this regard, screen-printed electrodes (SPEs) have been widely used for point-of-care testing applications with the aim of satisfying inexpert users. ${ }^{38}$ SPEs have the benefits of being cost-effective (due to having scales of economy), portability, provide useful analytical outputs and can be easily integrated within portable systems for on-site detection analysis. Furthermore, SPEs can be rapidly modified with nanomaterials to provide further enhancements in sensing performance toward target analytes, which improve electrochemical activity and hence analytical performances. ${ }^{39,40}$ To this end, we have electrochemically modified SPEs and tailored the electrode surface to provide a nanoparticle-modified sensor for the sensing of DPX. From this perspective, we have utilized $\mathrm{Au}-\mathrm{Cs}$ nanoparticle-modified SPEs to devise a new platform for the sensing of DPX. This sensor is based on the electrochemical codeposition of $\mathrm{Au}$ and $\mathrm{Cs}$ nanoparticles onto the surface of SPEs. Note that to the best of our knowledge, no dynamic electrochemical approaches have been reported to date for the sensing of DPX, but potentiometric sensing has been reported. ${ }^{41}$ The potential sensor was used for the analysis of DPX alone and in the presence of coformulated drug SIL simultaneously. The proposed electroanalytical methodology was fully validated according to International Conference on Harmonization (ICH) guidelines with further selectivity assessment in the presence of SIL as a coformulated PDE-5 inhibitor within pharmaceutical and biological samples.

\section{RESULTS AND DISCUSSION}

The electrochemical response of the $\mathrm{Cs}-\mathrm{Au} / \mathrm{SPE}$ was explored to evaluate its potential as the basis of a DPX sensor. The cyclic voltammetric response of the $\mathrm{Cs}-\mathrm{Au} / \mathrm{SPE}$ was explored toward the electrochemical oxidation of DPX and compared to $\mathrm{Au} /$ SPE, Cs/SPE, and a metallic-free unmodified SPE. Figure 1 depicts large and quantifiable electrochemical signatures in all cases. The $\mathrm{Cs}-\mathrm{Au} / \mathrm{SPE}$ exhibits the highest voltammetric signal $(67.8 \mu \mathrm{A} /+1.23 \mathrm{~V})$ analytical response at the lowest (see Experimental Section), and we surmise that upon the anodic scan, the $\mathrm{Cs}-\mathrm{Au}$ nanoparticles are not stripped off the electrode surface, allowing the electrochemical oxidation of DPX to occur. In the case of the Au/SPE and Cs/SPE, this is not the situation, and the corresponding electrochemical oxidation peaks of DPX are lower. Hence, the Cs-Au nanoparticles exhibit a beneficial synergistic effect. The Supporting Information provides further information on the characterization of the electrode surfaces and determination of the electrochemical active areas. The electrochemical properties of the potential sensor were further corroborated through

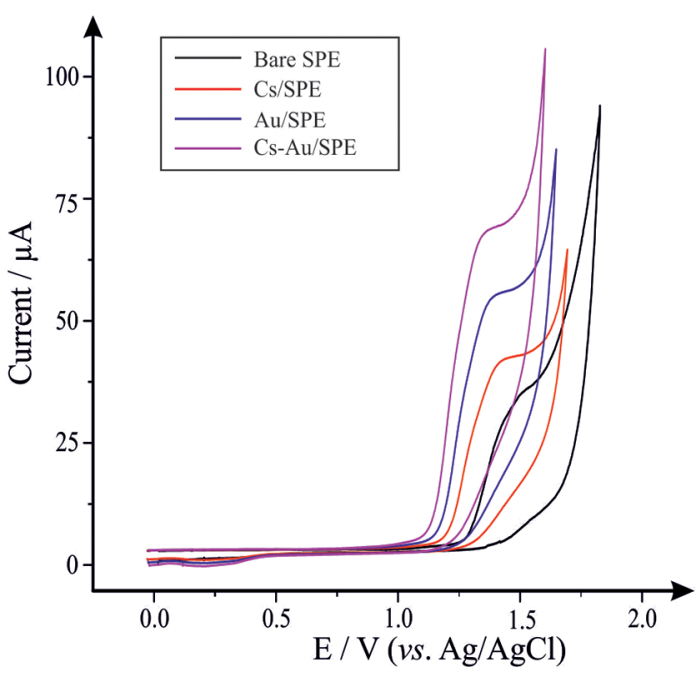

Figure 1. Cyclic voltammograms of $1.0 \mathrm{mM}$ DPX in the B-R buffer $(\mathrm{pH} 2.0)$ at a scan rate of $0.10 \mathrm{~V} \mathrm{~s}^{-1}$ recorded using SPE, Cs/SPE, Au/ $\mathrm{SPE}$, and $\mathrm{Cs}-\mathrm{Au} / \mathrm{SPE}$.

electrochemical impedance spectroscopy (EIS). Figure S1 displays the EIS response for the bare SPE, Cs/SPE, Au/SPE, and $\mathrm{Cs}-\mathrm{Au} / \mathrm{SPE}$, where the bare SPE gives rise to a large semicircle domain, indicating a high electron transfer resistance. Upon modifying the SPE with $\mathrm{Cs}$ or $\mathrm{Au}, R_{\mathrm{CT}}$ exhibits a small semicircle domain, indicating enhanced electrical conductivity. In the case of the $\mathrm{Cs}-\mathrm{Au} / \mathrm{SPE}, R_{\mathrm{CT}}$ decreases, indicating an increase in the electron-transfer kinetics. In summary, the electron-transfer resistance decreases in the following order: bare SPE $<\mathrm{Cs} / \mathrm{SPE}<\mathrm{Au} / \mathrm{SPE}<\mathrm{Cs}-\mathrm{Au} / \mathrm{SPE}$, which confirms the observations reported above (Figure 1), indicating that the combination of $\mathrm{Au}$ and $\mathrm{Cs}$ exhibits an excellent electrically conducting material.

Next, the effect of changing the solution $\mathrm{pH}$ upon the electrochemical oxidation of DPX using the Cs-Au/SPE was explored over the $\mathrm{pH}$ range of 2.0-7.0. As shown in Figure S4, the peak potentials $\left(E_{\mathrm{p}}\right)$ voltammetrically shift toward a less positive potential upon increasing the $\mathrm{pH}$ value from 2.0 to 7.0 , which can be attributed to the protonation/deprotonation of DPX. Figure S4 reveals the relationships of the peak current and peak potential with the solution $\mathrm{pH}$, where the peak current decreases with increasing $\mathrm{pH}$; based upon this data, $\mathrm{pH}$ 2 Britton-Robinson ( $\mathrm{B}-\mathrm{R}$ ) buffer was selected as the optimum $\mathrm{pH}$ for further studies. Analysis of the voltammetric responses (peak potential, $E_{\mathrm{p}}$ ) displays a linear relationship with $\mathrm{pH}$ of the buffer solution, which can be fitted as $E_{\mathrm{p}}(\mathrm{V})=1.35 \mathrm{~V}-52.4$ $\mathrm{mV} \mathrm{pH}^{-1}$; coefficient of determination $R^{2}=0.9997$; the value of $52.4 \mathrm{mV} / \mathrm{pH}$ is close to the theoretical value expected for an equal electron and proton process. As depicted in Figure S4, a well-developed anodic peak current was shown over the $\mathrm{pH}$ range from 2.0 to 7.0. However, a small-developed second peak starts to appear, which increases steadily with increasing $\mathrm{pH}$. Furthermore, on increasing the $\mathrm{pH}$ value up to 7.0, the first oxidation peak is observed to shift to a less-positive potential, indicating the irreversible behavior of the oxidation process, which is confirmed by the cyclic voltammetric analysis (see Figure 1). The corresponding peak decreases because of the hindrance of the oxidation process due to the reduced concentration of protons and strong adsorption of the oxidative products of DPX upon the electrode surface. This suggests that the $\mathrm{H}^{+}$ions were involved in the oxidation of the DPX 
molecule, and the deprotonation step proceeds before the electron-transfer step. The plot of the first peak potential versus $\mathrm{pH}$ exhibits a straight line between 2.0 and 7.0. From the inspection of the molecular structure of DPX, it can be seen that the anodic peak is likely because of the hydroxylation of the benzene ring, as reported previously using mercury, borondoped diamond, and glassy carbon electrodes. ${ }^{42,43}$ DPX has two suggested oxidation mechanism pathways. In acidic media, from $\mathrm{pH} 2 \rightarrow 4$, one anodic peak appears. This peak is likely because of the hydroxylation of the benzene ring. ${ }^{44}$ At $\mathrm{pH}$ values 5.0 and above, another anodic peak starts to appear as the DPX gives two separate anodic oxidation peaks. The second anodic peak appears likely because of the deprotonation of DPX and the formation of a cation radical via the loss of a proton and an electron. This second oxidation process appears in neutral and alkaline media because of the oxidation of the secondary amine group. ${ }^{44}$ The decrease in the anodic signal (peak current) is observed because of the appearance of the second oxidation step occurring at less positive potentials. Moreover, the anodic peak current of the first peak reaches its highest value at $\mathrm{pH} 2.0$ in the form of a sharp peak and was recorded as a single response in acidic media. On the basis of the above data, $\mathrm{pH} 2.0$ was selected for further electrochemical measurements. Nyquist plots for the $\mathrm{Cs}-\mathrm{Au} / \mathrm{SPE}$ at different $\mathrm{pH}$ values are shown in Figure S4B. The semicircle diameter and the impedance values increase with increasing $\mathrm{pH}$, indicating a decrease in the conductivity and giving the same order of the cyclic voltammetry $(\mathrm{CV})$ results.

Next, the effect of varying the voltammetric scan rate upon the electrochemical oxidation of DPX was investigated using $\mathrm{CV}$, as shown in Figure S5. The Cs-Au/SPE displays a linear relationship between the voltammetric current $\left(I_{\mathrm{p}}\right)$ and the square root of the scan rate $\left(v^{1 / 2}\right)$, as shown in Figure S5 (inset A), suggesting that the electrochemical process is diffusioncontrolled. The data can be fitted as $I_{\mathrm{p}}(\mu \mathrm{A})=-1.644+6.648 v$ $\left(\mathrm{V} \mathrm{s}^{-1}\right)^{-1 / 2}$ with a correlation coefficient of 0.9993 . The electrochemical oxidation peak potential $\left(E_{\mathrm{p}}\right)$ is also dependent upon the voltammetric scan rate, where increasing the scan rate results in a shift to more positive potentials; the linear relationship between $E_{\mathrm{p}}$ and $\log v$ can be described as $E_{\mathrm{p}}(\mathrm{mV})$ $=491 E(\mathrm{mV})+155.2\left(\mathrm{mV} \mathrm{s}^{-1}\right)\left(R^{2}=0.9998\right)$. Using the Laviron $^{45}$ equation for an irreversible electrochemical process, the electrochemical parameters of the electrochemical oxidation of DPX using the $\mathrm{Cs}-\mathrm{Au} / \mathrm{SPE}$ are found to be as follows: $\alpha n=$ $0.44, \alpha=0.44, E^{\mathrm{o} \prime}=1.20$, and $k^{\circ}=26.9 \mathrm{~s}^{-1}$. On the basis of the results obtained from the voltammetric experiments, the number of electrons transferred $(n)$ in the electrochemical process was calculated and found to be one, which is in agreement with the results obtained from the effect of $\mathrm{pH}$ described above.

Design of experiments for optimization is a beneficial technique to extract the effects of factors upon certain responses. As a common mathematical model for the prediction of factors affecting an analytical response, that is, in this case the peak current, the response surface method (RSM) was applied, which is an efficient optimization procedure that saves both cost and time. ${ }^{46,47}$ The RSM has the ability to estimate a second-order prediction formula along with interaction effects. However, it requires a large number of experiments in numerous factor designs. Therefore, factors should be limited in the first instance to apply the RSM. Screening for influential factors such as $\mathrm{pH}$, scan rate, along with deposition voltage and time was experimentally conducted beforehand. This study revealed that the scan rate, deposition time, and $\mathrm{pH}$ substantially affect the signal/current. A face-centered design was applied, which is a special type of central composite design for RSM optimization. Sixteen experiments were conducted in random order, including eight experiments at the vertices of the cube (code: + or - ), six experiments on face axial points (i.e., axial value $=1$; code: a or $\mathrm{A}$ ), and a center point (code: 0 ) repeated two times to improve the mathematical prediction model (Table 1).

Table 1. Levels of Studied Factors for Sixteen Experiments in the RSM Design with the Obtained Response

\begin{tabular}{|c|c|c|c|c|c|}
\hline \multirow[b]{2}{*}{$\begin{array}{l}\text { experiment } \\
\text { number }\end{array}$} & \multirow[b]{2}{*}{ pattern } & \multicolumn{3}{|c|}{ factors' level } & \multirow{2}{*}{$\begin{array}{c}\text { response } \\
\text { current } \\
(\mu \mathrm{A})\end{array}$} \\
\hline & & $\begin{array}{c}\text { scan rate } \\
(\mathrm{mV} / \mathrm{s})\end{array}$ & $\begin{array}{l}\text { deposition } \\
\text { time }(\mathrm{s})\end{array}$ & $\mathrm{pH}$ & \\
\hline 1 & +-+ & 50 & 30 & 4 & 42 \\
\hline 2 & -+- & 10 & 90 & 2 & 49 \\
\hline 3 & 0 & 30 & 60 & 3 & 41 \\
\hline 4 & $0 \mathrm{a} 0$ & 30 & 30 & 3 & 33 \\
\hline 5 & +-- & 50 & 30 & 2 & 46 \\
\hline 6 & ++- & 50 & 90 & 2 & 58 \\
\hline 7 & $\mathrm{a} 00$ & 10 & 60 & 3 & 31 \\
\hline 8 & --- & 10 & 30 & 2 & 29 \\
\hline 9 & -++ & 10 & 90 & 4 & 36 \\
\hline 10 & A00 & 50 & 60 & 3 & 59 \\
\hline 11 & +++ & 50 & 90 & 4 & 57 \\
\hline 12 & $00 \mathrm{~A}$ & 30 & 60 & 4 & 47 \\
\hline 13 & $0 A 0$ & 30 & 90 & 3 & 42 \\
\hline 14 & 0 & 30 & 60 & 3 & 40 \\
\hline 15 & --+ & 10 & 30 & 4 & 22 \\
\hline 16 & $00 \mathrm{a}$ & 30 & 60 & 2 & 42 \\
\hline
\end{tabular}

The mathematical prediction model for the current $(I)$ was calculated from the linear, quadratic, and interaction terms as follows

$$
\begin{aligned}
I= & 41.50+9.50 X_{1}+3.00 X_{1}^{2}+7.00 X_{2}-4.50 X_{2}^{2} \\
& -2.00 X_{3}+2.50 X_{3}^{2}-0.88 X_{1} X_{2}+1.88 X_{1} X_{3} \\
& -0.38 X_{2} X_{3}
\end{aligned}
$$

where $X_{1}, X_{2}$, and $X_{3}$ are the scan rate, the deposition time and $\mathrm{pH}$, respectively. The coefficient of determination $\left(R^{2}\right)$ of the model was found to correspond to 0.92 with the root mean square error found to be 4.67 , indicating an adequate fit of the prediction model. Comparing the coefficients of the main effects, we can conclude that the scan rate has the largest significant positive effect $(p=0.0007)$, and hence response would be maximized at a high level of this factor $(50 \mathrm{mV} / \mathrm{s})$. Another significant main effect is the deposition time ( $p=$ 0.0032 ), the large positive coefficient of $X_{2}$ provides that the long deposition time is favored. The last insignificant main factor is $\mathrm{pH}$ with a negative coefficient that in turn increases the design's target at its low level. All coefficients of quadratic terms are too small to be significant as noticed response surface curvatures in Figure 2. Note that the positive quadratic terms were registered for the scan rate and $\mathrm{pH}$, whereas a negative one was present for the deposition time. Therefore, opposite curvatures of contour lines were noticed in the deposition time response function with other factors (Figure 2A,C). Trivial interaction between the studied factors was also calculated in the prediction model, however, the largest coefficient of $X_{1} X_{3}$ 

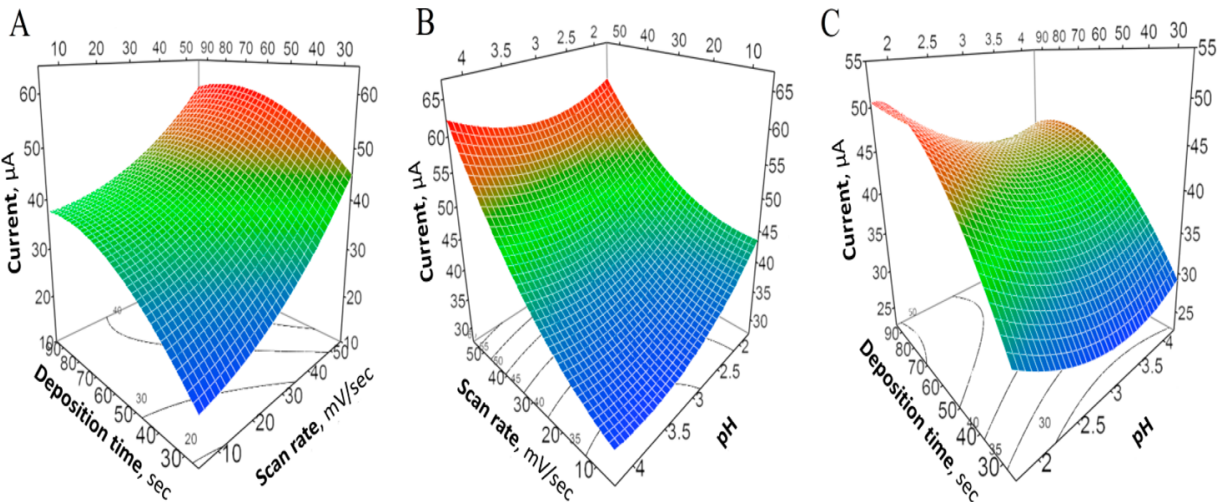

Figure 2. Surface plots summarizing the effects of different experimental parameters: (A) scan rate/deposition time, (B) $\mathrm{pH} / \mathrm{scan}$ rate, and (C) deposition time/pH upon the voltammetric current/analytical signal.
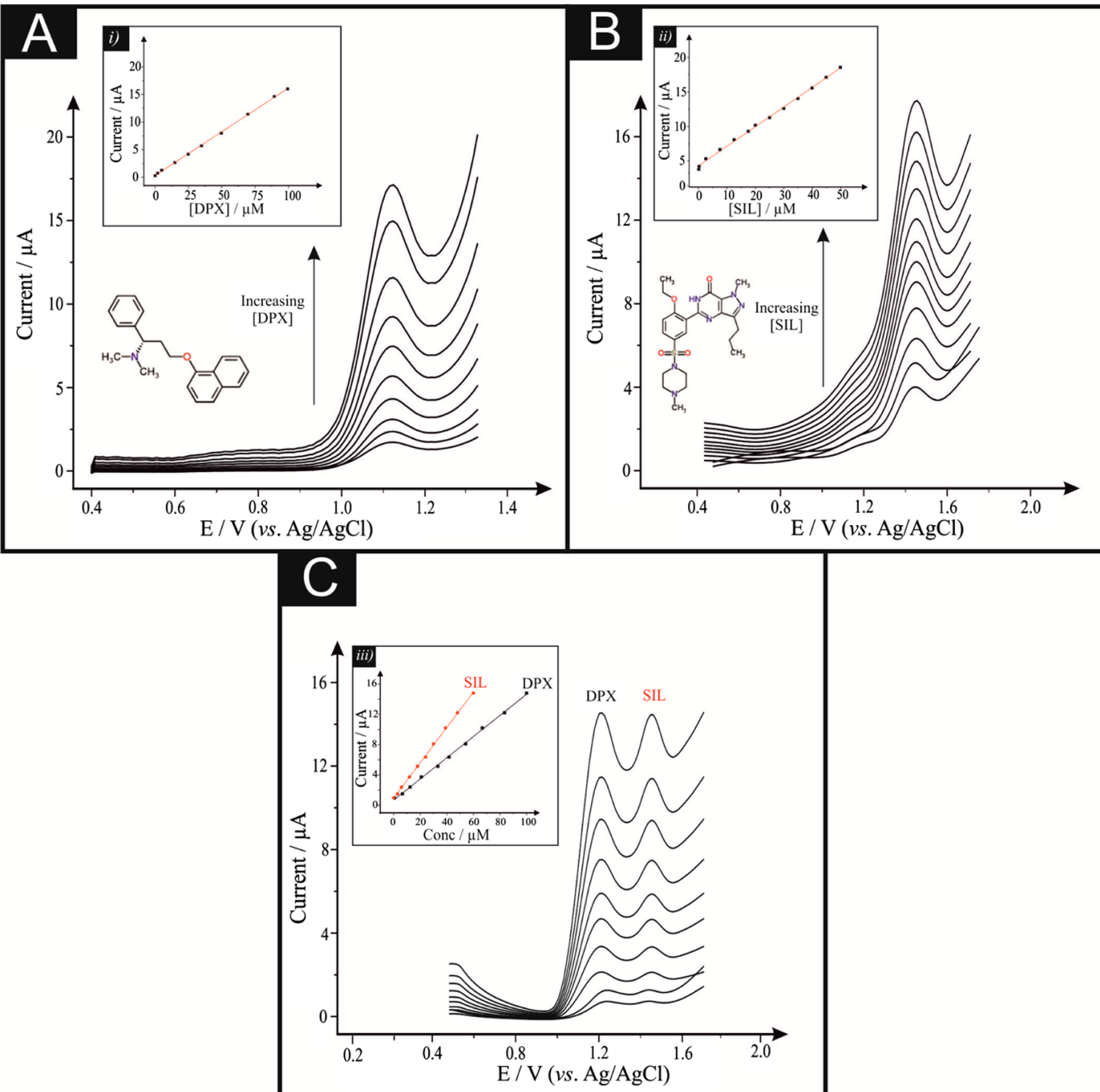

Figure 3. Square wave voltammograms using the $\mathrm{Cs}-\mathrm{Au} / \mathrm{SPE}$ sensors recorded in $\mathrm{pH} 2.0 \mathrm{~B}-\mathrm{R}$ buffer corresponding to (A) $1.0 \times 10^{-7}$ to $1.1 \times 10^{-3}$ $\mathrm{M} \mathrm{DPX}$ and (B) $5.0 \times 10^{-8}$ to $1.1 \times 10^{-3} \mathrm{SIL}$. (C) Square wave voltammograms of $6.6 \times 10^{-7}$ to $1.0 \times 10^{-4} \mathrm{M} \mathrm{DPX}$ in the presence of $5.0 \times 10^{-8}$ to $6.0 \times 10^{-5} \mathrm{M} \mathrm{SIL}$ at a scan rate of $0.05 \mathrm{~V} \mathrm{~s}^{-1}$ and their corresponding calibration curves.

indicates a possible interaction between the scan rate and $\mathrm{pH}$, as observed in the contour line curvature in Figure $2 \mathrm{~B}$. The final optimization suggested that using a scan rate of $50 \mathrm{mV} / \mathrm{s}$ and deposition time of $80 \mathrm{~s}$ at $\mathrm{pH} 2.0$ would maximize the obtained current.
The proposed Cs-Au/SPE-based sensor was next investigated through exploring the simultaneous detection of DPX and SIL. The optimized conditions for DPX determination via square wave voltammetry ( $\mathrm{SWV}, \mathrm{pH} 2.0$, scan rate: $0.05 \mathrm{~V} \mathrm{~s}^{-1}$, and $80 \mathrm{~s}$ for deposition) were used. The ICH guidelines ${ }^{48,49}$ for method validation were followed for validation of this suggested 
method. SWV experiments were performed using the $\mathrm{Cs}-\mathrm{Au} /$ SPE sensor in $\mathrm{pH} 2.0 \mathrm{~B}-\mathrm{R}$ buffer solution containing various individual concentrations of DPX. The calibration range used was chosen based upon the likely practical range that DPX concentrations will be encountered within real samples. The SWV results are presented in Figure 3 with the corresponding calibration plot (inset of Figure 3). The results show the peak currents corresponding to the electrochemical oxidation of DPX using the Cs-Au/SPE, which is found to be linearly dependent on DPX concentrations over the range of $1.0 \times 10^{-7}$ to $1.0 \times 10^{-4} \mathrm{M}\left[I_{\mathrm{p}}(\mu \mathrm{A})=0.147 \mathrm{C}(\mu \mathrm{M})+2.104 ; R^{2}=\right.$ 0.9995]. The calculated limit of detection (LOD) and the limit of quantitation (LOQ) were found to be $2.5 \times 10^{-8}$ and $8.3 \times$ $10^{-8} \mathrm{M}$, respectively. Note that this is the first voltammetric approach, and previously only ion-selective electrodes were reported with a linear range of $1.0 \times 10^{-4}$ to $1.0 \times 10^{-2} \mathrm{M}$, and the LOD was reported to be $2.0 \times 10^{-5} \mathrm{M}^{41}$ indicating that the $\mathrm{Cs}-\mathrm{Au} / \mathrm{SPE}$ is analytically advantageous. The stability of the $\mathrm{Cs}-\mathrm{Au} / \mathrm{SPE}$ was also explored, where the voltammetric peak current was found not to change following storage in air for 7 days; the sensor was found to retain $98.94-99.07 \%$ of its initial response. Furthermore, Figure $3 \mathrm{~B}$ depicts the square wave voltammograms for an array of varying concentrations of SIL over the range of $2.5 \times 10^{-8}$ to $5.0 \times 10^{-5} \mathrm{M}\left[I_{\mathrm{p}}(\mu \mathrm{A})=0.257 \mathrm{C}\right.$ $\left.(\mu \mathrm{M})+1.102 ; R^{2}=0.9991\right]$. The calculated values of LOD and LOQ were found to be $5.84 \times 10^{-9}$ and $1.95 \times 10^{-8}$, respectively. The repeatability and intermediate precisions were found to correspond to $0.891-0.902 \%$ and $0.957-1.08 \%$ for DPX and SIL, respectively.

The specificity of the Cs-Au/SPE was next explored with its electroanalytical response examined toward the sensing of DPX in the presence of the frequently coformulated drug SIL. This was performed by simultaneously changing the concentrations of these drugs and recording the square wave voltammograms on the $\mathrm{Cs}-\mathrm{Au} / \mathrm{SPE}$. Figure $3 \mathrm{C}$ shows the voltammetric response of using the $\mathrm{Cs}-\mathrm{Au} / \mathrm{SPE}$ sensor toward the sensing of DPX in the presence of SIL. The results showed well-defined anodic peaks at potentials of +1.2 and $+1.4 \mathrm{~V}$, corresponding to the oxidation of DPX and SIL, respectively, demonstrating that the simultaneous determination of DPX and SIL is feasible. The calibration plots (inset of Figure 3) are found to be linearly related to the concentrations of DPX and SIL over the ranges $6.6 \times 10^{-7}$ to $1.0 \times 10^{-4}$ and $5.0 \times 10^{-8}$ to $6.0 \times 10^{-8} \mathrm{M}$, respectively. The regression equations were $I_{\mathrm{p}}(\mu \mathrm{A})=0.140 \mathrm{C}$ $(\mu \mathrm{M})+0.910, R^{2}=0.9991$ and $I_{\mathrm{p}}(\mu \mathrm{A})=0.234 C(\mu \mathrm{M})+$ $0.931, R^{2}=0.9990$ for DPX and SIL, respectively. The electroanalytical sensitivities of the $\mathrm{Cs}-\mathrm{Au} / \mathrm{SPE}$ sensor toward the oxidation of DPX and SIL were found to be 0.140 and $0.234 \mu \mathrm{A} / \mu \mathrm{M}$, respectively; these values are very close to the value obtained for the independent determination of DPX and SIL (0.147 and $0.257 \mu \mathrm{A} / \mu \mathrm{M})$, demonstrating that the simultaneous determination of DPX and SIL is possible with useful analytical capabilities and sensitivities.

The presence of ascorbic acid (ASA) and uric acid (UA) were also explored upon the electrochemical oxidation of DPX (Figure S6) because these two analytes coexist in many biological samples. ${ }^{50}$ The electrochemical oxidation of $6.5 \times$ $10^{-6} \mathrm{M}$ DPX in the presence of $6.5 \times 10^{-6} \mathrm{M}$ ASA and UA were investigated using the $\mathrm{Cs}-\mathrm{Au} / \mathrm{SPE}$ via SWV, as shown in Figure S6, which demonstrates that these are far resolved from the analytical peak of interest. The effect of many substances that can potentially interfere with the electroanalytical determination of DPX were also examined. A range of potential interferences were chosen, which are commonly found in pharmaceutical formulations. Using a fixed DPX concentration of $6.5 \times 10^{-6} \mathrm{M}$ in $\mathrm{pH} 2.0 \mathrm{~B}-\mathrm{R}$ buffer solution, each of these substances was added, and the magnitude of the DPX signal was monitored. From the chosen potential interfering substances, none were found to interfere with the electroanalytical sensing of DPX, and the tolerance limit was less than $\pm 4 \%$ for each of the interference substances. The results showed that 100-fold of sucrose, glucose, fructose, lactose, and citric acid and 200-fold of potassium sorbate, stearic acid, talc powder, magnesium stearate, povidone, microcrystalline cellulose, starch, cellulose, colloidal silicon dioxide, and croscarmellose sodium did not affect the selectivity.

Calibration curves for the spiked plasma and urine were also constructed. The obtained regression equation and related validation parameters are reported in Table S1. The determination of DPX and SIL in the spiked blood plasma, urine, and the pharmaceutical sample (Joypox) tablets was done using the Cs-Au/SPE sensors (Table 2). The above

Table 2. Determination of DPX in a Pharmaceutical Formulation and Human Plasma Sample Using the New Proposed Sensing Protocol ${ }^{a}$

\begin{tabular}{|c|c|c|c|}
\hline sample & $\begin{array}{l}\text { amount added } \\
(\mu \mathrm{M})\end{array}$ & $\begin{array}{l}\text { amount found } \\
(\mu \mathrm{M})\end{array}$ & $\begin{array}{l}\text { apparent } \\
\text { recovery \% }\end{array}$ \\
\hline human blood plasma & 8.00 & 8.01 & $100.13 \%$ \\
\hline \multirow[t]{2}{*}{ DPX } & 20.00 & 19.89 & $99.45 \%$ \\
\hline & 70.00 & 69.97 & $99.96 \%$ \\
\hline recovery $\% \pm \mathrm{RSD}$ & & & $99.85 \% \pm 0.354$ \\
\hline \multirow[t]{3}{*}{ SIL } & 0.40 & 0.399 & $99.75 \%$ \\
\hline & 1.00 & 1.001 & $100.10 \%$ \\
\hline & 40.00 & 39.95 & $99.88 \%$ \\
\hline recovery $\% \pm \mathrm{RSD}$ & & & $99.91 \% \pm 0.177$ \\
\hline human urine & 6.00 & 5.96 & $99.33 \%$ \\
\hline \multirow[t]{2}{*}{ DPX } & 30.00 & 30.12 & $100.40 \%$ \\
\hline & 80.00 & 80.09 & $100.11 \%$ \\
\hline recovery $\% \pm \mathrm{RSD}$ & & & $99.95 \% \pm 0.553$ \\
\hline \multirow[t]{3}{*}{ SIL } & 0.60 & 0.597 & $99.50 \%$ \\
\hline & 1.50 & 1.509 & $100.60 \%$ \\
\hline & 30.00 & 30.25 & $100.83 \%$ \\
\hline recovery $\% \pm \mathrm{RSD}$ & & & $100.31 \% \pm 0.711$ \\
\hline \multirow{2}{*}{$\begin{array}{l}\text { Joypox } \\
\text { (60 mg/tablet) }\end{array}$} & 4.00 & 3.97 & $99.25 \%$ \\
\hline & 15.00 & 14.91 & $99.00 \%$ \\
\hline DPX & 90.00 & 89.95 & $99.94 \%$ \\
\hline recovery $\% \pm \mathrm{RSD}$ & & & $99.39 \% \pm 0.487$ \\
\hline
\end{tabular}

${ }^{a}$ Average of three determinations. RSD, relative standard deviation.

analytical results indicate that the $\mathrm{Cs}-\mathrm{Au} / \mathrm{SPE}$ is a highly accurate and sensitive sensor, which has further benefits of not requiring any intricate sample pretreatment and has potential as an analytical methodology for the determination of DPX and SIL in real samples.

\section{CONCLUSIONS}

In summary, we have reported for the first time, the electroanalytical sensing of DPX using a $\mathrm{Au}-\mathrm{Cs}$ nanoparticlebased sensor. This $\mathrm{Cs}-\mathrm{Au} / \mathrm{SPE}$ sensor exhibits low LOD and LOQ with a wide linear range and is shown to determine DPX in the existence of the frequently coformulated drug SIL without any interference. The Cs-Au/SPE sensor has been successfully applied for the determination of DPX within 
pharmaceutical samples and human plasma with satisfactory recoveries. In comparison of this proposed sensor to other analytical technologies such as chromatographic methods, the developed sensor is cost-effective, fast, potentially portable, and uses simpler instruments; and because of the outstanding analytical features of the sensor, the proposed sensor has the potential to be routinely used in the determination of DPX in biological samples.

\section{EXPERIMENTAL SECTION}

Materials and Reagents. DPX and SIL were kindly supplied by Pharco Pharmaceuticals, Alexandria, Egypt with a purity of 99.12 and $99.78 \%$, respectively; Joypox tablets, labeled to contain $60 \mathrm{mg}$ DPX per tablet, were purchased from a local pharmaceutical supplier (shop). B-R buffer $\left(4.0 \times 10^{-2} \mathrm{M}\right)$ was prepared by mixing $\mathrm{H}_{3} \mathrm{PO}_{4}$, acetic acid, and boric acid with the appropriate amount of $0.2 \mathrm{M} \mathrm{NaOH}$ to obtain the desired $\mathrm{pH}(2.0-7.0)$. Hydrogen-tetrachloroaurate $\left(\mathrm{HAuCl}_{4}\right)$, potassium permanganate, and sodium nitrate were purchased from Aldrich Ltd. Cesium chloride was obtained from Sigma-Aldrich. Fresh human serum was obtained from the blood bank (VACSERA, Cairo, Egypt). Further details of the instrumentation utilized are reported in the Supporting Information.

Preparation of the Cesium-Gold Nanoparticle Sensors (Cs-Au/SPE Sensors). SPEs were fabricated at the Manchester Metropolitan University. We have reported previously these fabrication steps; see ref 51 . The $\mathrm{Cs}-\mathrm{Au} /$ SPE sensors were fabricated through the electrochemical modification of the SPEs. Different concentrations of Cs, 2.0 $\times 10^{-3}, 4.0 \times 10^{-3}, 6.0 \times 10^{-3}$, and $8.0 \times 10^{-3} \mathrm{M}$ were explored. We found that $6.0 \times 10^{-3} \mathrm{M} \mathrm{Cs}$ is the optimal concentration with Au for codeposition. This was performed by immersing SPEs into a solution comprising $6.0 \times 10^{-3} \mathrm{M}$ $\mathrm{HAuCl}_{4}$ and $\mathrm{CsCl}_{2}$ in $0.1 \mathrm{M} \mathrm{KNO}_{3}$ at a constant potential of $-0.4 \mathrm{~V}$ (vs $\mathrm{Ag} / \mathrm{AgCl}$ ) for $80 \mathrm{~s}$ to form the Cs-Au/SPE-based surface, which forms the basis of the sensor. After this step, the sensor was washed with bidistilled water and left to dry at 25 ${ }^{\circ} \mathrm{C}$ for $45 \mathrm{~min}$. The $\mathrm{Cs}-\mathrm{Au} / \mathrm{SPEs}$ were then ready to use. Characterization of the $\mathrm{Cs}-\mathrm{Au} / \mathrm{SPE}$ is reported in the Supporting Information (Figure S2, SEM images; Figure S3, energy dispersive X-ray analysis (EDAX)).

Recommended Experimental Procedure. Cs-Au/SPE sensors were electrochemically cycled between the potentials of +0.8 and $-1.4 \mathrm{~V}$ versus $\mathrm{Ag} / \mathrm{AgCl}$ at a scan rate of $0.1 \mathrm{~V} \mathrm{~s}^{-1}$ within $\mathrm{pH} 2.0 \mathrm{~B}-\mathrm{R}$ buffer to determine the voltammetric current from the baseline to the maximum point.

Analysis of Real Samples. Serum samples were taken from a healthy individual just before the experiments. Ten microliters of the supernatant were transferred quantitatively into a $5 \mathrm{~mL}$ volumetric flask spiked with different volumes of DPX and SIL standard solution $(1.0 \mathrm{mM})$ in $\mathrm{pH} 2.0 \mathrm{~B}-\mathrm{R}$ buffer solution. The solution was transferred into the electrochemical cell to be analyzed without any further pretreatment.

Urine was collected from healthy donors in the morning, free of interfering drugs. Blank urine samples were collected from five subjects, which were then used to prepare urine standards for validation. Urine standards were prepared by dilution with $\mathrm{pH} 2.0 \mathrm{~B}-\mathrm{R}$ buffer solution containing DPX. All urine samples were prepared and analyzed on the day of collection. All experiments were performed in compliance with the relevant laws and institutional guidelines, and the institutional committees have approved these experiments.
Six capsules of Joypox were mixed and weighed with the average mass per tablet determined. These were then dissolved in $50.0 \mathrm{~mL}$ of methanol and sonicated for $60 \mathrm{~min}$. The solution was then filtered into a $25.0 \mathrm{~mL}$ volume calibrated flask, and the residue was washed three times with methanol, added to the flask, and then diluted to the mark with the same solvent.

\section{ASSOCIATED CONTENT}

\section{Supporting Information}

The Supporting Information is available free of charge on the ACS Publications website at DOI: 10.1021/acsomega.7b01193.

Experimental details; physicochemical characterization of the $\mathrm{Cs}-\mathrm{Au} / \mathrm{SPE}$; and regression data of the calibration curve for the quantitative determination of DPX and SIL using the Cs-Au/SPE in spiked human plasma and urine (PDF)

\section{AUTHOR INFORMATION}

\section{Corresponding Authors}

*E-mail: c.banks@mmu.ac.uk (C.E.B.).

*E-mail: nageh.allam@aucegypt.edu (N.K.A.).

ORCID

Christopher W. Foster: 0000-0002-5487-2803

Craig E. Banks: 0000-0002-0756-9764

Nageh K. Allam: 0000-0001-9458-3507

\section{Notes}

The authors declare no competing financial interest.

\section{ACKNOWLEDGMENTS}

The authors acknowledge a British Council Institutional Link grant (No. 172726574).

\section{REFERENCES}

(1) Vineeta, V. K.; Muralikrishna, K. S. Development and Validation of UV Spectrophotometric method for estimation of Dapoxetine HCL in bulk and dosage Form. Int. J. Drug Dev. Res. 2013, 5, 161-167.

(2) Sexual Medicine: Sexual Dysfunctions in Men and Women; Lue, T., Basson, R., Rosen, R., Giuliano, F., Khoury, S., Montorsi, F., Eds., Distributor ed, 2004; Vol. 21.

(3) Hatzimouratidis, K.; Amar, E.; Eardley, I.; Giuliano, F.; Hatzichristou, D.; Montorsi, F.; Vardi, Y.; Wespes, E. Guidelines on male sexual dysfunction: erectile dysfunction and premature ejaculation. Eur. Urol. 2010, 57, 804-814.

(4) Fasolo, C. B.; Mirone, V.; Gentile, V.; Parazzini, F.; Ricci, E.; Andrology Prevention Week Centers; Italian Society of Andrology (SIA). Premature ejaculation: prevalence and associated conditions in a sample of 12,558 men attending the andrology prevention week 2001-a study of the Italian Society of Andrology (SIA). J. Sex. Med. 2005, 2, 376-382.

(5) Zhang, W.-m.; Qiang, W.; Ying-fei, W.; Ming, S.; Wang, R. Development and validation of a sensitive UPLC-MS/MS method for the simultaneous determination of dapoxetine and its two metabolites in human plasma. J. Pharm. Biomed. Anal. 2016, 119, 45-49.

(6) USP, D. Drug Information for the Health Care Professional, 25th ed.; The United States Pharmacopeial Convention. Inc.: Rockville, sildenafil (systemic) monograph, 2005.

(7) Buvat, J.; Tesfaye, F.; Rothman, M.; Rivas, D. A.; Giuliano, F. Dapoxetine for the treatment of premature ejaculation: results from a randomized, double-blind, placebo-controlled phase 3 trial in 22 countries. Eur. Urol. 2009, 55, 957-968.

(8) Speranza, L.; Franceschelli, S.; Pesce, M.; Vinciguerra, I.; De Lutiis, M.; Grilli, A.; Felaco, M.; Patruno, A. Phosphodiesterase type-5 inhibitor and oxidative stress. Int. J. Immunopathol. Pharmacol. 2008, 21, 879-889. 
(9) Ghoneim, M. M.; Hassanein, A. M.; Salahuddin, N. A.; ElDesoky, H. S.; Elfiky, M. N. Trace determination of vardenafil hydrochloride in commercial formulation and human serum by adsorptive anodic stripping voltammetry at a carbon paste electrode. J. Solid State Electrochem. 2013, 17, 1891-1902.

(10) Wang, W.-F.; Wang, Y.; Minhas, S.; Ralph, D. J. Can sildenafil treat primary premature ejaculation? A prospective clinical study. Int. J. Urol. 2007, 14, 331-335.

(11) Mattos, R. M.; Lucon, A. M.; Srougi, M. Tadalafil and fluoxetine in premature ejaculation: prospective, randomized, double-blind, placebo-controlled study. Urol. Int. 2008, 80, 162-165.

(12) Malard, L. M.; Pimenta, M. A.; Dresselhaus, G.; Dresselhaus, M. S. Raman spectroscopy in graphene. Phys. Rep. 2009, 473, 51-87.

(13) Skalicka-Woźniak, K.; Georgiev, M. I.; Orhan, I. E. Adulteration of herbal sexual enhancers and slimmers: The wish for better sexual well-being and perfect body can be risky. Food Chem. Toxicol. 2016, DOI: $10.1016 /$ j.fct.2016.06.018, In press.

(14) Şentürk, Z.; Saka, C.; Teğin, İ. Analytical methods for determination of selective serotonin reuptake inhibitor antidepressants. Rev. Anal. Chem. 2011, 30, 87-122.

(15) Saka, C.; Şahin, Ö. Determination of Serotonin-Norepinephrine Reuptake Inhibitor Antidepressants in Pharmaceuticals and Biological Material. Crit. Rev. Anal. Chem. 2013, 43, 2-34.

(16) Lebel, P.; Gagnon, J.; Furtos, A.; Waldron, K. C. A rapid, quantitative liquid chromatography-mass spectrometry screening method for 71 active and 11 natural erectile dysfunction ingredients present in potentially adulterated or counterfeit products. $J$. Chromatogr. A 2014, 1343, 143-151.

(17) Li, L.; Low, M.-Y.; Ge, X.; Bloodworth, B. C.; Koh, H.-L. Isolation and structural elucidation of dapoxetine as an adulterant in a health supplement used for sexual performance enhancement. J. Pharm. Biomed. Anal. 2009, 50, 724-728.

(18) Liew, K. B.; Peh, K. K. Stability indicating HPLC-UV method for determination of dapoxetine $\mathrm{HCl}$ in pharmaceutical product. Acta Pol. Pharm. 2014, 71, 393.

(19) Chabukswar, A. P.; Kuchekar, B. S.; Patil, S. L.; Moon, S. A.; Chate, S. G.; Pagare, B. D. Spectrophotometric simultaneous determination of dapoxetine and sildenafil in combined tablet dosage form by absorbance corrected method. Der Pharma Chem. 2012, 4, 1404-1407.

(20) Patil, R. B.; Deshmukh, T. A.; Patil, V. R. Stability indicating HPLC method for dapoxetine $\mathrm{HCl}$ in bulk and in formulation. Int. J. Pharm. Pharm. Sci. 2014, 6, 687-690.

(21) Soliman, S. M.; El-Agizy, H. M. Y.; El Bayoumi, A. E. A. Derivative synchronous fluorescence spectroscopy for the simultaneous determination of dapoxetine hydrochloride and vardenafil in binary mixtures. J. Appl. Spectrosc. 2014, 81, 509-518.

(22) Patel, M. N.; Kothari, C. S. Multivariate Approaches for Simultaneous Determination of Avanafil and Dapoxetine by UV Chemometrics and HPLC-QbD in Binary Mixtures and Pharmaceutical Product. J. AOAC Int. 2016, 99, 649-663.

(23) Savjiyani, N. B.; Patel, P. B. Simultaneous estimation of vardenafil hydrochloride and dapoxetine hydrochloride in combined pharmaceutical dosage form by spectrophotometry and RP-HPLC. Indo Am. J. Pharm. Res. 2013, 3, 3652-3668.

(24) Giri, A. D.; Bhusari, V. K.; Dhaneshwar, S. R. Validated HPLC method for simultaneous quantitation of tadalafil and dapoxetine hydrochloride in bulk drug and formulation. Int. J. Pharm. Pharm. Sci. 2012, 4, 654-658.

(25) Abdel-Moety, M. M.; Souaya, E. R.; Soliman, E. A. Spectrophotometric methods for simultaneous determination of vardenafil and dapoxetine hydrochlorides in combined dosage form. World J. Pharm. Pharm. Sci. 2015, 4, 120-133.

(26) Baker, M. M.; Belal, T. S.; Mahrous, M. S.; Ahmed, H. M.; Daabees, H. G. High-performance liquid chromatography with diode array detection method for the simultaneous determination of seven selected phosphodiesterase-5 inhibitors and serotonin reuptake inhibitors used as male sexual enhancers. J. Sep. Sci. 2016, 39, $1656-1665$.
(27) Hegazy, M.; Kessiba, A.; Abdelkawy, M.; El-Gindy, A. E. RPHPLC with Time Programmed Fluorescence Detection for Quantitation of Avanafil and Dapoxetine Hydrochloride: Application to Pharmaceutical Dosage Form and Biological Fluid. J. Liq. Chromatogr. Relat. Technol. 2015, 38, 1660-1665.

(28) Hegazy, M.; Kessiba, A.; Abdelkawy, M.; El-Gindy, A. E. A novel liquid chromatographic method with fluorescence detection for quantitation of tadalafil and dapoxetine hydrochloride in pharmaceutical dosage form and human plasma. Chin. J. Chromatogr. 2015, 33, 765-770.

(29) Rajeshwari, M.; Chenthilnathan, A.; Rama, K. Validated RPHPLC method for simultaneous estimation of tadalafil and dapoxetine hydrochloride in combined pharmaceutical dosage forms. Int. J. Pharm. Biol. Sci. 2014, 4, 72-82.

(30) Hamilton, C. L.; Cornpropst, J. D. Determination of dapoxetine, an investigational agent with the potential for treating depression, and its mono- and di-desmethyl metabolites in human plasma using column-switching high-performance liquid chromatography. J. Chromatogr., Biomed. Appl. 1993, 612, 253-261.

(31) Neumajer, G.; Sohajda, T.; Darcsi, A.; Tóth, G.; Szente, L.; Noszál, B.; Béni, S. Chiral recognition of dapoxetine enantiomers with methylated-gamma-cyclodextrin: A validated capillary electrophoresis method. J. Pharm. Biomed. Anal. 2012, 62, 42-47.

(32) Kim, T. K.; Kim, I. S.; Hong, S. H.; Choi, Y. K.; Kim, H.; Yoo, H. H. Determination of dapoxetine in rat plasma by ultra-performance liquid chromatography-tandem mass spectrometry. J. Chromatogr. B: Anal. Technol. Biomed. Life Sci. 2013, 926, 42-46.

(33) Mohamed, M. A.; Yehia, A. M.; Banks, C. E.; Allam, N. K. Novel MWCNTs/graphene oxide/pyrogallol composite with enhanced sensitivity for biosensing applications. Biosens. Bioelectron. 2017, 89, 1034-1041.

(34) Smith, J. P.; Metters, J. P.; Khreit, O. I. G.; Sutcliffe, O. B.; Banks, C. E. Forensic Electrochemistry Applied to the Sensing of New Psychoactive Substances: Electroanalytical Sensing of Synthetic Cathinones and Analytical Validation in the Quantification of Seized Street Samples. Anal. Chem. 2014, 86, 9985-9992.

(35) Teeparuksapun, K.; Hedström, M.; Kanatharana, P.; Thavarungkul, P.; Mattiasson, B. Capacitive immunosensor for the detection of host cell proteins. J. Biotechnol. 2012, 157, 207-213.

(36) Afkhami, A.; Khoshsafar, H.; Bagheri, H.; Madrakian, T. Preparation of $\mathrm{NiFe} 2 \mathrm{O} 4 /$ graphene nanocomposite and its application as a modifier for the fabrication of an electrochemical sensor for the simultaneous determination of tramadol and acetaminophen. Anal. Chim. Acta 2014, 831, 50-59.

(37) Mohamed, M. A.; Atty, S. A.; Salama, N. N.; Banks, C. E. Highly Selective Sensing Platform Utilizing Graphene Oxide and Multiwalled Carbon Nanotubes for the Sensitive Determination of Tramadol in the Presence of Co-Formulated Drugs. Electroanalysis 2017, 29, 10381048.

(38) Brotons, A.; Mas, L. A.; Metters, J. P.; Banks, C. E.; Iniesta, J. Voltammetric behaviour of free DNA bases, methylcytosine and oligonucleotides at disposable screen printed graphite electrode platforms. Analyst 2013, 138, 5239-5249.

(39) Li, Q. W.; Li, Y.; Zhang, X. F.; Chikkannanavar, S. B.; Zhao, Y. H.; Dangelewicz, A. M.; Zheng, L. X.; Doorn, S. K.; Jia, Q. X.; Peterson, D. E.; Arendt, P. N.; Zhu, Y. T. Structure-dependent electrical properties of carbon nanotube fibers. Adv. Mater. 2007, 19, 3358-3363.

(40) Mahmoud, B. G.; Khairy, M.; Rashwan, F. A.; Banks, C. E. Simultaneous Voltammetric Determination of Acetaminophen and Isoniazid (Hepatotoxicity-related Drugs) utilizing Bismuth Oxide Nanorod Modified Screen-printed Electrochemical Sensing Platforms. Anal. Chem. 2017, 89, 2170-2178.

(41) Aziz, A.; Khamees, N.; Mohamed, T. A.-F.; Derar, A. R Comparative Study of PVC-Free All-Solid-State, PVC Membrane, and Carbon Paste Ion-Selective Electrodes for the Determination of Dapoxetine Hydrochloride in Pharmaceutical Formulation. J. AOAC Int. 2016, 99, 1499-1504. 
(42) Gupta, A. K.; Sindal, R. S. A comparative study of electrochemical reduction of isatin and its synthesized Schiff bases at HMDE. J. Chem. Sci. 2009, 121, 347-351.

(43) Kul, D.; Gumustas, M.; Uslu, B.; Ozkan, S. A. Electroanalytical characteristics of antipsychotic drug ziprasidone and its determination in pharmaceuticals and serum samples on solid electrodes. Talanta 2010, 82, 286-295.

(44) Adenier, A.; Chehimi, M. M.; Gallardo, I.; Pinson, J.; Vilà, N. Electrochemical oxidation of aliphatic amines and their attachment to carbon and metal surfaces. Langmuir 2004, 20, 8243-8253.

(45) Laviron, E. General expression of the linear potential sweep voltammogram in the case of diffusionless electrochemical systems. J. Electroanal. Chem. Interfacial Electrochem. 1979, 101, 19-28.

(46) Bezerra, M. A.; Santelli, R. E.; Oliveira, E. P.; Villar, L. S.; Escaleira, L. A. Response surface methodology (RSM) as a tool for optimization in analytical chemistry. Talanta 2008, 76, 965-977.

(47) Leardi, R. Experimental design in chemistry: a tutorial. Anal. Chim. Acta 2009, 652, 161-172.

(48) Mohamed, M. A.; Abdelwahab, N. S.; Banks, C. E. Electroanalytical sensing of the antimicrobial drug linezolid utilising an electrochemical sensing platform based upon a multiwalled carbon nanotubes/bromocresol green modified carbon paste electrode. Anal. Methods 2016, 8, 4345-4353.

(49) Guideline, I. H. T. Q2B Validation of Analytical Procedures: Methodology. Fed. Regist, 1997; Vol. 62.

(50) Ahmed, H. M.; Mohamed, M. A.; Salem, W. M. New voltammetric analysis of olanzapine in tablets and human urine samples using a modified carbon paste sensor electrode incorporating gold nanoparticles and glutamine in a micellar medium. Anal. Methods 2015, 7, 581-589.

(51) Khairy, M.; Khorshed, A. A.; Rashwan, F. A.; Salah, G. A.; Abdel-Wadood, H. M.; Banks, C. E. Sensitive determination of amlodipine besylate using bare/unmodified and DNA-modified screen-printed electrodes in tablets and biological fluids. Sens. Actuators, B 2017, 239, 768-775. 